\title{
Quality of Life and Menopause in Women with Physical Disabilities
}

\author{
CLAIRE Z. KALPAKJIAN, Ph.D., and ANTHONY LEQUERICA, Ph.D.
}

\begin{abstract}
Objective: The goal of this cross-sectional study was to explore quality of life (QOL) in a sample of postmenopausal women with physical disabilities due to polio contracted in childhood. A structural equation model was used to confirm that menopause symptoms will have a minimal effect on QOL when disability-related variables are taken into account.

Methods: A sample of 752 women who were postmenopausal completed a written survey. The structural equation model contained two measured predictors (age, severity of postpolio sequelae) and one latent predictor (menopause symptoms defined by four measured indicators). Functional status (defined by two measured indicators) was included as a mediator, with QOL (defined by three measured indicators) as the outcome.

Results: The original model yielded acceptable fit indices (CFI $=0.96$, RMSEA $=0.055)$ but resulted in a number of unexpected relationships that proved to be artifacts after model respecification. The respecified model yielded a nonsignificant chi-square value, which indicated no significant discrepancy between the proposed model and the observed data (chisquare $=18.5, d f=13, p=0.138$ ). All fit indices indicated a good fit: $\mathrm{CFI}=0.997, \mathrm{NNFI}=$ 0.987, chi-square/d $f=1.43$, and RMSEA $=0.024$ ).

Conclusions: When the effects of postpolio sequelae and functional status are included in the structural equation model, only the psychological symptoms of menopause play a prominent role in explaining QOL in this sample. The clinical implications of these findings suggest that attention to psychological symptoms and an exclusive focus on the physical aspects of menopause to the exclusion of other midlife life stressors and influences on a woman's psychological well-being ignore the larger context of life in which they live. In particular, many women with disabilities may contend with additional or exacerbated stressors related to their disability.
\end{abstract}

\section{INTRODUCTION}

W ITH ADVANCES IN HEALTHCARE and management of chronic and disabling conditions, women with physical disabilities are living longer than previous generations and transitioning through menopause in greater numbers than ever before. ${ }^{1}$ Of the 30 million women with physical disabilities in the United States, more than 16 million are over the age of 50 years, ${ }^{2}$ constituting a large and growing population of women whose transition through menopause has received scant attention in the empirical literature.

Much of the extant literature agrees that the

Department of Physical Medicine and Rehabilitation, University of Michigan Health System, Ann Arbor, Michigan.

We thank Post-Polio Health International for their generous financial support of this project. 
relationship between quality of life (QOL) and menopause is complex and multilayered, with socioeconomic, vocational, and personal factors having a strong influence on QOL for women as they transition through menopause. Kuh et al. ${ }^{3}$ found that life course trajectories that included neuroticism or antisocial behavior and prior experience of mental or physical health problems in adult life predisposed some women to greater psychological distress in midlife above and beyond menopause. In the areas of physical health, psychosomatic status, and personal life, Mishra and $\mathrm{Kuh}^{4}$ found that among middle-aged women, the top risk factor for declines in QOL for these three areas was work or family stress; menopause status was associated with the two first areas but not personal life. Other studies have found that a direct association of QOL and menopause was attenuated when other factors, such as marriage and perceived stress, were accounted for. ${ }^{5}$

Greene ${ }^{6}$ has proposed a vulnerability model of menopause, arguing that the state of menopause makes some women more vulnerable to psychological distress associated with middle age, such as life stress, family stress, or bereavement. In other studies, experiencing menopause as stressful has been associated with higher levels of neuroticism, avoidance, seeking social support, and lower agreeableness. ${ }^{7,8}$ Mood disturbance during perimenopause and early postmenopause also has been associated with stressful life events around middle age, such as bereavement, caring for children and aging parents, and health problems. $^{9-11}$

The role of stress at menopause and its impact on QOL and well-being in general have particular relevance for polio survivors, given lifelong health problems and, for many of them, a reemergence of polio-related health problems in middle age, characterized by new or progressive muscle weakness, joint and muscle pain, and fatigue, which can emerge after years of stability. ${ }^{12,13}$ In fact, women with disabilities in general can experience additional or more acute stressors in midlife compared with their nondisabled peers. A more vulnerable health status, fewer vocational opportunities, less financial stability, isolation, higher rates of physical abuse, and stigma can compound typical midlife stressors for many women with disabilities. ${ }^{14-16}$

Polio survivors have often been characterized as determined, hard working, and capable of overcoming a multitude of barriers to achieve both personal and professional success. ${ }^{17-20} \mathrm{Nev}$ ertheless, early difficult and traumatic experiences surrounding the onset of acute polio, such as sudden separation from their loved ones, illness, and rehabilitation, ${ }^{20}$ have all been shown to impact psychological functioning later in life. In a study by Schanke et al., ${ }^{21}$ individuals who reported being psychologically harmed during their acute illness reported, many years later, significantly more pain, using more analgesics and sedatives, and greater fatigue, sleep disturbance, and nightmares than those who did not report such early psychological harm. They also reported significantly greater emotional distress and lower QOL.

Although, compared with controls, polio survivors in general may report lower levels of $\mathrm{QOL}_{1}^{22,23}$ these levels themselves are not necessarily low. For example, high levels of satisfaction in domains of family life and sexual functioning 23,24 have been found, and a number of studies have found generally high levels of QOL and happiness among polio survivors. ${ }^{25-28}$ Psychosocial factors, such as social support and acceptance of disability, also have been associated with QOL in polio survivors. ${ }^{24,28,29}$ It is unknown if these early experiences may have some influence on the experience of menopause, as suggested by Hardy and Kuh's research ${ }^{3,4}$ and Greene's vulnerability model. ${ }^{6}$

Investigations into the unique influence of physical disability and its effect on the experience of menopause are rooted in the overarching question of whether women who have contended with a physical disability have developed effective coping mechanisms, perspectives, and outlooks that positively or negatively influence QOL experienced during the menopause transition. Given the complexity of the relationship of QOL and menopause and the potential vulnerability of certain women to experience increased stress and a decline in QOL at menopause, the goal of this study was to explore QOL in a sample of postmenopausal women with physical disabilities caused by polio. A structural equation modeling (SEM) approach was used to confirm the expectation that menopause symptoms will have a minimal effect on QOL when disability-related variables are taken into account. It was also expected that age and severity of postpolio sequelae would be only indirectly associated with QOL through their influence on functional status. 


\section{MATERIALS AND METHODS}

\section{Participants}

In 2003-2004, a study of menopause, aging, and polio was conducted at a large midwestern university. Letters of invitation to participate, along with a response card, were sent to 2964 individuals (women and men) from a mailing list provided by Post-Polio Health International. Potential participants were instructed to return the response card if they wished to receive a survey. A total of 1548 people were sent surveys, and 1282 were returned. Of these, 909 women completed the survey. From this larger sample, a total of 752 women met the criteria for being postmenopausal (defined by a minimum of 12 months since the final menstrual period).

\section{Measures}

A written survey mailed to participants' homes comprised measures and nonstandardized items. Domains of the survey included general health status, presence of health problems and postpolio sequelae, physical functioning, emotional well-being, polio history, and menopause history. Relevant domains from this survey for the purpose of this current analysis are described here.

QOL and emotional well-being. The Satisfaction with Life Scale (SWLS) ${ }^{30}$ is designed to measure a global, cognitive judgment of one's life. Items are rated on a Likert scale ranging from 1 (strongly disagree) to 7 (strongly agree). Scores range from 5 to 35 , such that higher scores indicate greater life satisfaction. In this study, internal consistency was 0.89 .

The Positive and Negative Affect Scale (PANAS) $^{31}$ is a widely used measure of positive and negative affect. Ten positive and ten negative affect descriptors are rated on a Likert scale ranging from 1 (very slightly or not at all) to 5 (extremely). Scores for the positive and negative scales range from 0 to 50 , respectively, such that higher scores indicate greater positive or negative affect. Only the Positive Affect Scale was used as one subjective dimension of QOL in this study. The internal consistency was 0.89 for the positive scale.

Physical functioning and postpolio sequelae. The Functional Status Questionnaire (FSQ) ${ }^{32}$ was originally developed for comprehensive and effi- cient assessment of physical, psychosocial, social, and role functioning in ambulatory medical patients. The two scales of physical functioning, Basic Activities of Daily Living (BADL) and Intermediate Activities of Daily Living (IADL), were used in this study. Both scales are rated on 5-point Likert scales ranging from 1 (usually did not do because of health) to 4 (usually did with no difficulty). The BADL scale comprises three items referring to basic self-care ability (e.g., bathing and dressing, walking indoors); the IADL contains six items referring to more demanding selfcare activities (e.g., walking, driving a car, grocery shopping).

Total scores (after transformation) range from 0 to 100; scores falling below 88 on the BADL and below 78 on the IADL are considered to be in the warning zone, suggesting reduced ability to perform ADLs. In this study, internal consistency (Cronbach's alpha) was 0.70 for the BADL and 0.85 for the IADL.

A new measure developed by the investigators was used in the larger study to assess postpolio sequelae severity. The development and validation of this scale are described elsewhere. ${ }^{33}$ The Index of Post Polio Sequelae (IPPS) comprises 12 commonly reported postpolio sequelae rated on a 5-point Likert scale ranging from 1 (slight) to 5 (extreme). Total scores on the IPPS range from 0 to 60 , such that higher scores indicate greater severity of postpolio sequelae. In this study, internal consistency for the IPPS was 0.80; scores were normally distributed.

Menopause symptoms. The Menopause Symptom List (MSL) ${ }^{34}$ is a 25 -item scale of symptoms commonly associated with menopause. Items are rated for frequency and severity using 6-point Likert scales. Frequency scores range from 0 (never) to 5 (almost always), and severity scores range from 0 (not applicable) to 5 (extreme). We performed a factor analysis of the MSL with a subsample of women from this study, and those findings are reported elsewhere. ${ }^{35}$ Briefly, this factor analysis resulted in four factors. Factor 1 (psychological) consists of eight items that exactly replicate the psychological factor on the original MSL. Factor 2 (somatic-sensory) comprises two items related to sensory loss and two related to dehydration. Factor 3 (somatic-sleep) comprises two items related to sleep disturbance and two items related to vascularity. Factor 4 comprises two items that describe the core elements of va- 
somotor symptoms, namely, hot flushes and sweating. Internal consistency values for each of the four factor scales in this sample were 0.90, $0.64,0.65$, and 0.76, respectively. Because menopause symptoms range along different domains, as suggested by this and other factor analytical studies, an aggregate score has little meaning in and of itself ${ }^{36}$ and may obscure important differences between symptom clusters. ${ }^{37}$ Accordingly, scores for each factor scale, not a total score, were used in all of the analysis.

\section{Data analysis}

Data were analyzed using SPSS 12.0 and AMOS 5.0 statistical software (Chicago, IL). The AMOS feature to estimate means and intercepts was used to deal with missing data. This was decided after preliminary analyses showed that using this method with the full sample (vs. only women with complete data) resulted in outcomes comparable to results obtained when cases with a missing data point were completely removed. An SEM was used to examine the relationship between postpolio sequelae and menopausal symptoms (predictors) and subjective QOL. An advantage of using SEM is the ability to include latent or unobserved variables in the model. The latent variables are unobserved, theoretical constructs that are defined by a number of indicators, or measured variables. In the SEM, latent variables are represented by circles, whereas observed variables are represented by rectangles.

To determine how well the theoretical model represented the observed data, the chi-square statistic was generated, and a number of fit indices were examined. Based on suggestions for favorable model fit provided by Kline, ${ }^{38}$ the following criteria were set for assessing the fit of the theoretical model proposed in this study: (1) a nonsignificant goodness-of-fit chi-square statistic, (2) a chi-square to degrees of freedom $(d f)$ ratio of $<3$, and (3) values on the comparative fit index $(\mathrm{CFI})$ and nonnormed fit index (NNFI) $>0.90$. The CFI and NNFI range from 0 to 1 , where 0 reflects no fit, and 1 indicates that the theoretical model perfectly fits the observed data. ${ }^{38}$ The root mean square error of approximation (RMSEA) was also examined as a fourth criterion. $\mathrm{Hu}$ and Bentler ${ }^{39}$ have suggested that RMSEA $\leq 0.06$ should indicate a good model fit.

A number of additional statistics were generated for examination in this study. Some of these values can be seen in Figures 1 and 2. The values used to label double-headed arrows can be viewed as correlation coefficients indicating the strength of relationship between two variables, much like the Pearson correlation coefficient. The values used to label single-headed arrows are standardized direct effect coefficients (SDEC). They also indicate the strength of a direct relationship between two variables, much like standardized regression coefficients. Because these values are standardized, they typically range from 0 to 1 , with higher values indicating a stronger relationship between variables.

Other statistics not shown in the figures are the standardized indirect effect coefficient (SIEC) and the Sobel test statistic (STS). The SIEC represents an indirect effect of a predictor variable through a mediator to the outcome variable. It is frequently derived by taking the product of the SDEC between the predictor and mediator and the SDEC between the mediator and the outcome. Again, higher values indicate a stronger indirect effect. To test the significance of the indirect effect, the STS was conducted using specialized software. ${ }^{40}$

In creating the theoretical model for this study, in addition to age and postpolio sequelae, a number of additional measured variables were used as indicators for three latent variables: menopause symptoms, functional status, and QOL. The scores from four subscales from the MSL were used as indicators of menopause symptoms. Functional status was operationally defined by two indicators drawn from the FSQ scales, BADL and IADL. The Positive Affect subscale of the PANAS and the SWLS were used as indicators representing QOL.

Therefore, the SEM contained two measured predictors (age, severity of postpolio sequelae) and one latent predictor (menopause symptoms defined by four measured indicators). Functional status (defined by two measured indicators) was included as a mediator, with QOL (defined by two measured indicators) included as the outcome. Double-headed arrows were used to represent correlations between variables, and direct effects were depicted by single-headed arrows.

The model was arranged to reflect hypothesized relationships among variables. A good model fit and significant associations between variables in the predicted directions would lend support to the following hypotheses: 
Hypothesis 1. Increased age in postmenopausal women will be associated with a decrease in menopause symptoms. Increased age is also expected to be associated with a decline in functional status.

Hypothesis 2. The greater the severity of postpolio sequelae, the lower the functional status.

Hypothesis 3. The lower the functional status, the lower QOL is expected to be.

Hypothesis 4. Age and postpolio sequelae will influence QOL only indirectly through their effects on functional status.

Hypothesis 5. Greater menopause symptom severity may be associated with a decline in functional status. However, this effect should be minimal when age and postpolio sequelae are included in the model.

Hypothesis 6. With the influence of age, postpolio sequelae, and functional status on QOL accounted for in the model, the effect of menopause symptom severity on QOL is expected to be a very small, inverse relationship.

\section{RESULTS}

\section{Sociodemographic characteristics}

Demographic information for the present sample of 752 women is shown in Table 1. The majority of women in the sample identified themselves as white, non-Hispanic, generally distributed among the four regions of the United States (northeast, midwest, south and west). Overall, they were well educated, with over half of the sample reporting a college education; over $20 \%$ of the sample continued on to receive graduate training. More than half of the women were married, and less than one quarter of the sample was separated or divorced. Although the majority of the women were retired, more than one quarter of the sample reported they were currently working full-time or part-time.

Ages ranged from 42 to 91 years $(\mathrm{M}=64.8$, $\mathrm{SD}=8.5$ ). All women were at least 32.9 years postonset of the poliovirus and at least 1 year past their last menstrual period. Although the time since last menstrual period was considered to be an important variable, its relationship with other variables was accounted for when age was included in the analysis.

\section{Descriptive statistics}

Prior to performing the major analyses, descriptive statistics were generated for the variables to be included in the SEM. Descriptive statistics and Pearson correlations among measures are given in Tables 2 and 3, respectively.

\section{Structural equation model}

With a total of 38 parameters estimated in the model, the sample size $(n=752)$ was sufficiently large and above the number of cases recommended for testing such a model $(>10$ times the number of parameters estimated). The model,

Table 1. Demographic Characteristics of Sample ${ }^{a}$

\begin{tabular}{|c|c|}
\hline Demographic variable & $\mathrm{n}=752$ \\
\hline \multicolumn{2}{|l|}{ Ethnicity } \\
\hline African American & $6(0.8)$ \\
\hline Asian & $2(0.3)$ \\
\hline Caucasian & 727 (96.7) \\
\hline Latina & $7(0.9)$ \\
\hline Other & $2(0.3)$ \\
\hline Multiple ethnicity & $8(1.1)$ \\
\hline \multicolumn{2}{|l|}{ Level of education } \\
\hline Less than high school & $10(1.3)$ \\
\hline High school or GED & $132(17.6)$ \\
\hline Some college & $224(29.8)$ \\
\hline College degree & $215(28.6)$ \\
\hline Graduate degree & $170(22.6)$ \\
\hline Missing values & $1(0.1)$ \\
\hline \multicolumn{2}{|l|}{ Marital status } \\
\hline Married & $457(60.8)$ \\
\hline Divorced or separated & $112(14.9)$ \\
\hline Widowed & $93(12.4)$ \\
\hline Never married & $88(11.7)$ \\
\hline Missing values & $2(0.3)$ \\
\hline \multicolumn{2}{|l|}{ Occupational status } \\
\hline $\begin{array}{l}\text { Working full-time or } \\
\text { part-time }\end{array}$ & $190(25.3)$ \\
\hline $\begin{array}{l}\text { Unemployed, looking } \\
\text { for job }\end{array}$ & $2(0.3)$ \\
\hline Retired, not medical & $192(25.5)$ \\
\hline Retired, medical & $274(36.4)$ \\
\hline Homemaker & $93(12.4)$ \\
\hline $\begin{array}{l}\text { Retired both medical } \\
\text { and nonmedical }\end{array}$ & $1(0.1)$ \\
\hline Age (years) & $64.8 \pm 8.5$ \\
\hline Age at polio onset (years) & $8.6 \pm 7.0, n=750$ \\
\hline Years postonset & $56.2 \pm 7.4, n=750$ \\
\hline $\begin{array}{l}\text { Years since last menstrual } \\
\text { period }\end{array}$ & $18.4 \pm 10.6, n=750$ \\
\hline
\end{tabular}

aValues are given as numbers with percentage in parentheses and as mean \pm SD. 
Table 2. Descriptive Statistics

\begin{tabular}{lrcc}
\hline & Mean & $\begin{array}{c}\text { Standard } \\
\text { deviation }\end{array}$ & Range \\
\hline Index of postpolio sequelae & 25.2 & 10.2 & $0-56$ \\
MSL1-Psychological symptoms & 10.0 & 6.7 & $0-32$ \\
MSL2-Somatic-sensory symptoms & 3.8 & 3.2 & $0-13$ \\
MSL3-Somatic-sleep symptoms & 5.4 & 3.2 & $0-14$ \\
MSL4-Vasomotor symptoms & 2.9 & 2.5 & $0-10$ \\
Basic ADL & 79.8 & 20.4 & $0-100$ \\
Intermediate ADL & 48.7 & 27.7 & $0-100$ \\
Positive affect & 33.4 & 7.4 & $10-50$ \\
Life satisfaction & 21.8 & 7.4 & $5-35$ \\
\hline
\end{tabular}

shown in Figure 1, yielded some fit indices within the desirable range: $\mathrm{CFI}=0.96, \mathrm{NNFI}=0.93$, and RMSEA $=0.057$ (90\% CI 0.045-0.070). However, it also yielded a significant chi-square value, 93.6, $d f=27, p \leq 0.001$, suggesting a significant discrepancy between the theoretical model and the observed data. In addition, the chi-square/ $d f$ ratio of 3.5 fell above the cutoff for indicating a good-fitting model. Because the model had a number of satisfactory fit indices, it was further examined in relation to previously hypothesized relationships to determine if it might be modified to improve the goodness of fit.

\section{Hypothesis testing}

Hypothesis 1. Age was inversely associated with menopause symptoms $(r=-0.41, p \leq 0.001)$ and functional status (SDEC $=-0.15, p<0.001$ ). Although the relationship between age and functional status was significant and in the expected direction, it indicated a rather weak association.

Hypothesis 2. The standardized direct effect coefficient between postpolio sequelae and func- tional status (SDEC $=-0.63, p<0.001)$ indicated an inverse relationship, such that individuals with more severe symptoms were less able to perform ADL, supporting Hypothesis 2.

Hypothesis 3. QOL was associated with functional status in the expected direction $(\mathrm{SDEC}=$ $0.35, p<0.001$ ), supporting Hypothesis 3 .

Hypothesis 4. As expected, the inclusion of the indirect pathways for both age and postpolio sequelae through functional status to QOL resulted in nonsignificant direct pathways to QOL for both age (SDEC $=0.02, p=0.62$ ) and postpolio sequelae $(\mathrm{SDEC}=-0.05, p=0.44)$. To test the significance of these indirect effects, the STS was used. The indirect effect of age on QOL through functional status was significant but extremely weak $($ SIEC $=-0.05, \quad$ STS $=-2.8$, $p=0.004)$. The indirect effect of postpolio sequelae on QOL through functional status was shown to be significant and somewhat greater in magnitude (SIEC $=-0.22$, STS $=-5.0, p \leq$ 0.001).

Table 3. Bivariate Correlations among Study Variables $(n=752)$

\begin{tabular}{|c|c|c|c|c|c|c|c|c|c|c|}
\hline & 1 & 2 & 3 & 4 & 5 & 6 & 7 & 8 & 9 & 10 \\
\hline 1. Age & 1 & & & & & & & & & \\
\hline 2. Postpolio sequelae & 0.01 & 1 & & & & & & & & \\
\hline 3. MSL-Psychological & $-0.32^{*}$ & $0.30^{*}$ & 1 & & & & & & & \\
\hline 4. MSL-Somatic-sensory & $-0.15^{*}$ & $0.39^{*}$ & $0.36^{*}$ & 1 & & & & & & \\
\hline 5. MSL-Somatic-sleep & $-0.28^{*}$ & $0.37^{*}$ & $0.56^{*}$ & $0.38^{*}$ & 1 & & & & & \\
\hline 6. MSL-Vasomotor & $-0.27^{*}$ & $0.22^{*}$ & $0.45^{*}$ & $0.22^{*}$ & $0.36^{*}$ & 1 & & & & \\
\hline 7. Basic ADL & $-0.16^{*}$ & $-0.42^{*}$ & -0.03 & $-0.07^{*}$ & -0.07 & 0.01 & 1 & & & \\
\hline 8. Intermediate ADL & $-0.21^{*}$ & $-0.42^{*}$ & 0.03 & -0.03 & -0.01 & 0.05 & $0.62^{*}$ & 1 & & \\
\hline 9. Life satisfaction & 0.07 & $-0.34^{*}$ & $-0.32^{*}$ & $-0.16^{*}$ & $-0.16^{*}$ & $-0.16^{*}$ & $0.28^{*}$ & $0.22^{*}$ & 1 & \\
\hline 10. Positive affect & 0.06 & $-0.22^{*}$ & $-0.25^{*}$ & $-0.09 *$ & $-0.18^{*}$ & $-0.15^{*}$ & $0.19^{*}$ & $0.17^{*}$ & $0.53^{*}$ & 1 \\
\hline
\end{tabular}

${ }^{*}$ Correlation is significant at the 0.05 level (2-tailed). 


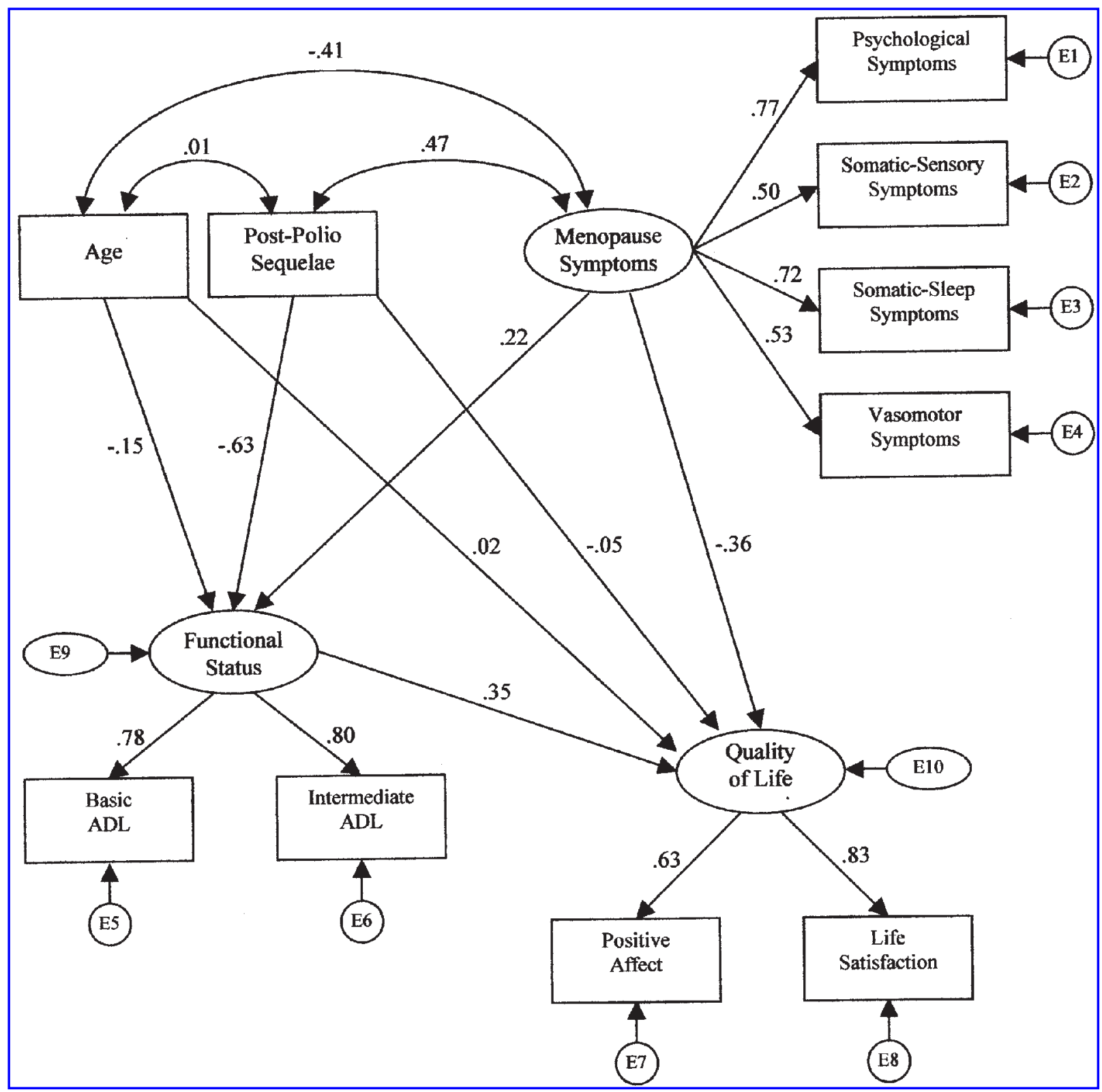

FIG. 1. Structural equation model (SEM) showing the impact of age, symptom severity, and functional status on QOL in postmenopausal women with postpolio syndrome.

Hypothesis 5. Although menopause symptom severity is significantly correlated with functional status (SDEC $=0.22, p \leq 0.001$ ), this relationship is weak in magnitude and normally should not be given much importance. However, more troubling is the fact that the model suggests a positive relationship (i.e., as menopause gets worse, functioning gets better). It is possible that this relationship reflects not a causal association but rather a spurious correlation resulting from the inverse relationship that menopause symptoms and functional status both share with age. In other words, functional status and menopause symptom severity in postmenopausal women both decrease as age increases. A restriction of range with regard to age may be an unavoidable consequence of examining postmenopausal women in which the youngest women in the sample, those closest to the time of their last menstrual period, tend to report more severe symptoms of menopause than the older women in the sample.

Hypothesis 6. The direct effect of menopause symptom severity on QOL was significant and in 
the expected direction $(\mathrm{SDEC}=-0.36, p \leq$ 0.001). However, the size of the relationship was larger than expected. Because the indicators of QOL were correlated with the psychological symptom factor of the MSL (Table 3), it is possible that the effect of menopause symptoms on QOL may be driven by this indicator of menopause symptom severity, with the physical symptoms of menopause showing no significant relationship with QOL.

In summary, there were two instances where menopause symptoms showed unexpected relationships with other variables. Because the model did not meet the criteria for goodness of fit, it is possible that these unexpected relationships may indicate problems with the model. The model was respecified by removing the latent variable representing menopause symptoms and treating its four indicators as separate predictor variables in order to examine how each individual menopause symptom factor affects functional status and QOL.

\section{Revised model testing}

In the revised model (Fig. 2), the relationship between menopause symptoms and functional status was estimated to see if the previous relationship was, in fact, a spurious correlation rather than a genuine or true effect. The model was also examined to see the individual contributions to QOL made by each of the menopause symptom factors, with the expectation that the psychological symptoms would show a significant rela-

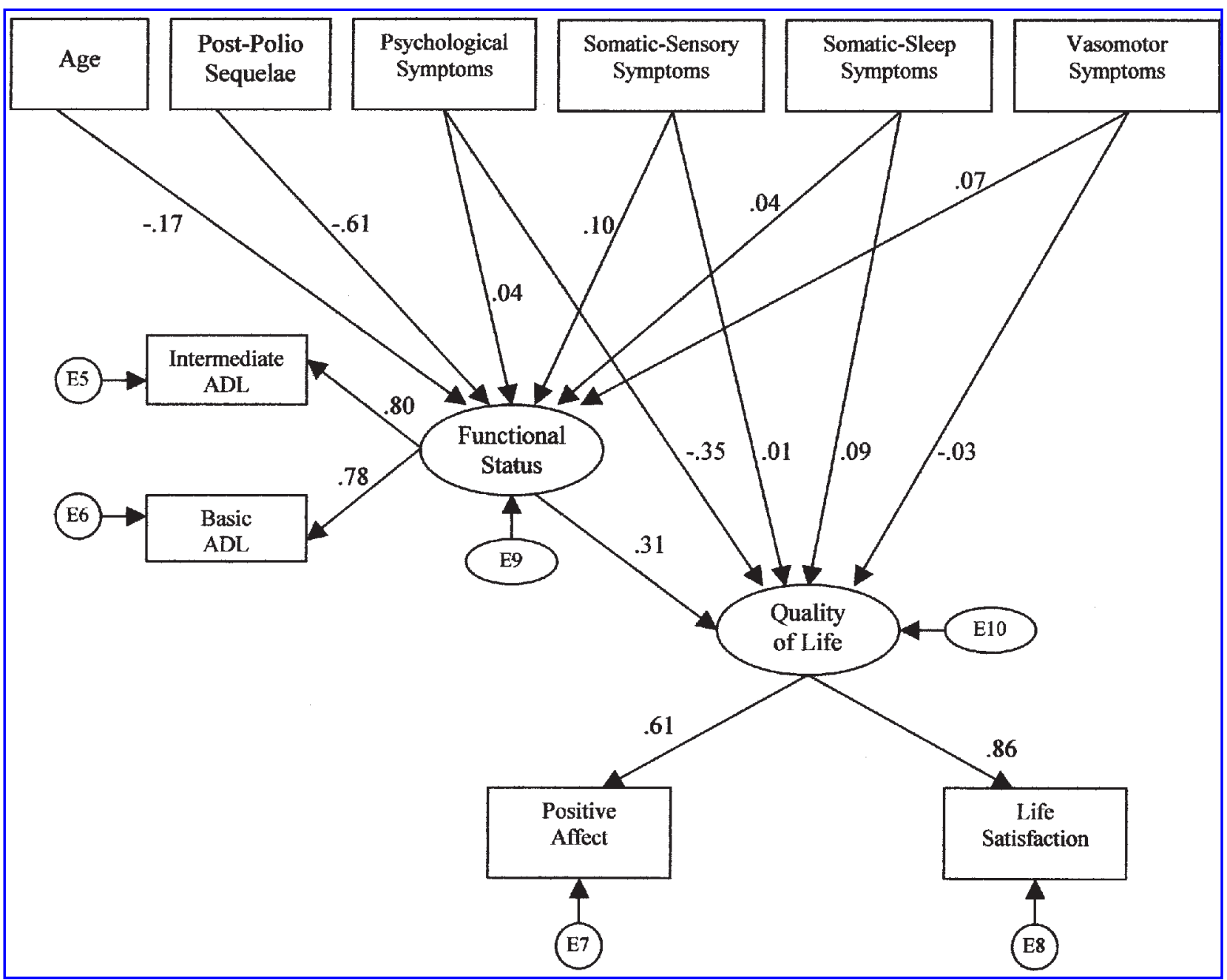

FIG. 2. Revised structural equation model (SEM) after respecification. Intercorrelations among predictors were estimated by the model but are not depicted here, for the purpose of simplicity. See Table 3 for the correlation matrix with all interrelationships. The direct effects of severity of postpolio sequelae (SDEC $=-0.16, p=0.005)$ and age (SDEC $=$ $0.07, p=0.120$ ) on QOL were also estimated in the analysis but omitted from this figure for the sake of clarity. 
tionship with QOL whereas the physical symptoms would not.

Testing of the revised model revealed a significant relationship between the psychological symptom factor and QOL $(\mathrm{SDEC}=-0.35, p \leq$ 0.001 ). In addition, none of the physical menopause symptom factors showed significant relationships with either functional status or QOL > 0.10 . This respecified model yielded a nonsignificant chi-square value, which indicated no significant discrepancy between the proposed model and the observed data (chi-square $=18.5$, $d f=13, p=0.138$ ). All fit indices indicated a good fit: $\mathrm{CFI}=0.997$, NNFI $=0.987$, chi-square $/ d f=$ 1.43 , and RMSEA $=0.024,90 \%$ CI $0.000-0.046$ ).

\section{DISCUSSION}

The present study showed that when the effects of postpolio sequelae and functional status are included in a structural equation model, only the psychological symptoms of menopause play a prominent role in explaining QOL in this sample of postmenopausal polio survivors. Physical menopause symptoms, on the other hand, such as somatic-sensory, somatic-sleep, and vasomotor symptoms, do not play a prominent role in explaining functional status or QOL in this sample of women. This is not an entirely surprising finding given the research on QOL and disability. The concept of response shift has been identified as key to measuring QOL in relation to changes in health status. Response shift refers to a change in the evaluation of QOL as a result of changes in internal standards, values, and conceptualizations. ${ }^{41}$ For example, changes related to aging with a physical disability and the attendant shifts in functional independence can serve as a catalyst for the process of response shift. Some investigators also speculate that unattainable goals (e.g., physically demanding) may be devalued, and those things that are achievable become more highly valued in an effort to enhance QOL after disability. ${ }^{42,43}$ In this study, women who have contended with a lifelong disability may not consider physical symptoms to have the same negative impact on QOL as a nondisabled woman may; therefore, its direct impact on QOL is negligible, as found in this study. Instead, its effect is mediated through its impact on physical functioning and, in turn, its impact on independence. This is supported by other studies that have sim- ilarly found the severity of the condition or injury impacts QOL via its effects on functioning. ${ }^{44}$

The initial model did not meet all the criteria used to determine goodness of fit and generated two values that represented relationships with menopause symptoms that were contrary to expectations. The first unexpected relationship suggested that a decrease in menopause symptom severity was associated with a decrease in functional status, yet there are no known studies that support this relationship. Furthermore, this was not a very strong relationship and could be linked to a relationship with a third variable, namely, age. Because the present sample consisted of women who were postmenopausal, menopause symptoms subside as age increases, as expected. Another effect of increasing age was a decline in functional status. These relationships between age and both menopause symptom severity and functional status were evident in the negative values generated by the model. It was, therefore, hypothesized that the apparent relationship between menopause symptom severity and functional status was a spurious correlation resulting from the manner in which both variables were similarly affected by age. This was confirmed in the respecified model when no significant relationships were observed between menopause symptoms and functional status.

The second unexpected relationship was noted between menopause symptom severity and QOL, suggesting that as menopause symptom severity increased, QOL decreased. Although this relationship was in the expected direction, it was larger than anticipated. Because significant associations were noted in the correlation matrix between the psychological symptom factor and the QOL indicators and because this relationship with QOL was stronger than the other menopause symptom factors, it was believed that this psychological symptom factor may be responsible for the seemingly strong relationship between menopause symptom severity and QOL. A better fitting model was obtained by allowing functional status to be associated with each of the four menopause symptom factors as individual, observed variables. This suggests that the physical symptoms of menopause have no direct impact on QOL in the present sample when the effects of age and disability are included in the model.

In addition, functional status was shown to act as a mediator in the relationship between postpolio sequelae and QOL, such that age and post- 
polio sequelae affect QOL only indirectly through the mediating effects of functional status. In other words, postpolio sequelae appear to affect QOL only indirectly through functional status. As discussed, this finding is not surprising. A significant but weaker indirect effect was found between age and QOL through functional status.

In this current study, psychological symptoms exerted the most direct and powerful effect on QOL, highlighting the complexity of factors influencing the experience of menopause. Caltabiano and Holzheimer ${ }^{45}$ examined the influence of optimism, "health-related hardiness," and "sense of coherence" on menopause symptom experience. Health-related hardiness refers to commitment, challenge, and control that are expressed when faced with a health challenge, such as chronic illness. For individuals with high levels of health-related hardiness, illness is appraised as a challenge rather than threat. Sense of coherence refers to the ability to reasonably anticipate life events, the degree to which one believes that actions can fulfill needs, and the capacity to find some aspect of the environment worthy of personal investment. Low levels of sense of coherence have been associated with higher anxiety and depression. In the study by Caltabiano and Holzheimer ${ }^{45}$ optimism and sense of coherence were shown to have a direct and positive effect on symptoms and psychological distress. The indirect effects of these three factors on the experience of menopause appeared to work through problemfocused coping vs. emotion-focused coping or attitudes. Others also have found that coping styles and personality influence stress experienced at menopause. ${ }^{7}$

These studies have important implications for understanding the experience of menopause and its subsequent effects on QOL in women with physical disabilities, particularly with regard to health-related hardiness, associated with positive appraisals of illness, and coping. Although health-related hardiness did not have a direct effect on QOL in Caltabiano and Holzheimer's sample, ${ }^{45}$ for women who contend daily with the effects of disability, its effect may be different. For example, the lifelong experience of disability may inoculate some women against distress associated with menopause symptoms; furthermore, physical changes or decline may be less associated with QOL for these women, who evaluate the quality of their lives on nonphysical criteria, as discussed above in regard to response shift.
This may help to explain the absence of a direct relationship between the physical menopause symptoms and QOL in this sample of women.

Problem-focused coping had a positive effect on QOL in Caltabiano and Holzheimer's study 45 and has been found to be similarly effective in the context of disability and postpolio in particular. Problem-focused coping is characterized by the use of strategies to solve problems ${ }^{46}$ and differs from emotion-focused coping in that its efforts are toward changing the situation rather than the perception of the situation. In general, polio survivors have been shown to use a high level of problem-focused coping. ${ }^{29,47}$ Although not directly measured in this current study, problemfocused coping practiced over a lifetime may serve these women well as they transition through menopause.

Hardy, Kuh, et al. ${ }^{3,48-51}$ have written extensively about the influence of early life experiences, social context, and their influence on the experience of menopause. In particular, the stress experienced during menopause can be attributed, in part, to other life experiences and the psychosocial context of a woman's life. For example, Kuh et al. ${ }^{3}$ found that after accounting for recent life stress, women with a high level of psychological distress at midlife had prior experience of mental and physical health problems in adult life, scored high on neuroticism scales and exhibited antisocial behavior in adolescence, and had more parental divorce in childhood.

Early commentaries written during the polio epidemics of the 1940s and 1950s reflect a deep understanding of the emotional impact of polio. ${ }^{52,53}$ Anecdotal reports and case histories describe powerful and traumatic early polio experiences of many survivors. In Wennenberg and Ahlstrom's qualitative study ${ }^{20}$ of early traumatic experiences and later psychological distress, three fourths of their sample said that the sudden separation from their loved ones, illness, and rehabilitation were traumatic. The reemergence of a disease once thought to have been conquered and its potential to trigger early memories has been cited as making a substantial contribution to diminished psychological well-being experienced by polio survivors. ${ }^{20,54-57}$ It is possible that such early traumatic experiences may also influence distress experienced in midlife and is worthy of further study.

This study's findings suggest that issues beyond physical status can have influence over 
emotional states in these polio survivors. Some studies have found no association between postpolio sequelae and psychological distress. ${ }^{22,55,57}$ In others, such symptoms as fatigue, ${ }^{58}$ pain, ${ }^{59-61}$ low energy, ${ }^{62}$ poor health rating, ${ }^{61}$ more somatic complaints, ${ }^{63}$ and diminished physical mobility ${ }^{64}$ have been associated with elevated levels of psychological distress. As noted earlier, individual perception, attribution, and meaning have been found to be more powerful predictors of psychological distress than objective findings in the context of illness and disability. ${ }^{55,65}$

\section{Clinical implications}

The clinical implications of these findings suggest that attention to psychological symptomsnot exclusive to menopause but also other psychosocial stressors, particularly in regard to aging and disability for women-is important, given their influence on QOL found in this study. An exclusive focus on menopause to the exclusion of myriad other life stressors and influences on a woman's psychological well-being in midlife ignores the larger context of life in which they live. In particular, many women with disabilities may contend with additional or exacerbated stressors related to their disability. ${ }^{15}$ These findings regarding functional status and QOL also emphasize the importance of maximizing functional status through evidence-based rehabilitation practices and finding new ways to effectively perform ADL through new techniques, compensatory strategies, and advances in assistive technology.

\section{Limitations and directions for future research}

Although there are some advantages to having a demographically homogeneous sample, such as this one, when exploring uncharted territory (thereby reducing confounders, many of which may not yet be identified), race and ethnicity can impact the experience of menopause symptoms, and, thus, findings from this study cannot be generalized to other non-Caucasian populations of women with physical disabilities. Future studies should involve more diverse samples and include those psychosocial factors known to impact menopause symptom experience to better understand how they, in turn, interact with physical disability. Future research should also include an age-matched control group of nondisabled women in postmenopause to further investigate the impact of disability on QOL in postmenopausal women.

The advent of the polio vaccine in 1955 essentially eradicated the disease in the United States, and as a result, very few women who had polio are in early middle age and in premenopause and perimenopause. Their older age, hence postmenopausal status, and less severe symptoms in general likely impacted findings. Future studies aiming to understand the interaction of disability and menopause should involve women with other disabling conditions that allow for a broader range of the menopause continuum and greater variability in menopause symptoms, which may produce different results from those found in this study. For example, it is likely that the spurious correlation found in this study between the latent menopause symptoms variable and functional status may have been generated by a restriction of range with regard to age and menopause symptom severity.

Large samples are always desirable, but interpretation of findings must be tempered by the increased likelihood of obtaining statistical significance. In such cases, even the smallest differences between groups and the smallest correlation coefficients appear to be significant. In this respect, the size of the relationship should be evaluated and understood in the context of what would be clinically or practically significant.

Because the measurement of menopause symptoms in the context of disability and accounting for overlap is essentially unprecedented in the literature, we cannot be certain that the MSL adequately captures menopause symptoms that are most likely to interact with disability (which will vary also by disability characteristics). In fact, for this study, symptoms not captured by the MSL may account for the lack of association between physical symptoms of menopause and functional status. Furthermore, there is a question of whether the MSL or similar scales will capture those symptoms that are of greatest concern to women with disabilities or those symptoms or conditions that produce the highest risk of further health problems for these women, such as osteoporosis or cardiovascular disease. Qualitative research methods often can capture the richness and complexity of how physical symptoms are experienced and may be the best mode to explore this question further. Similarly, measures of functional status via self-report are inherently limited with respect to objective indices of func- 
tioning that would otherwise be obtained by physical examination. The measurement itself may be limited in the degree to which it captures the breadth of functional activities performed on a daily basis. Use of the FSQ itself may attenuate associations with physical menopause symptoms as well.

\section{CONCLUSIONS}

Understanding the influence of menopause on QOL is complex in and of itself; empirical research has shown that there are many different factors that influence a woman's experience of menopause and, hence, the quality of her life during this transition. The additional layer of complexity that disability brings further challenges our understanding of how the pieces of this intricate puzzle fit together-how disability impacts menopause, and how menopause impacts disability. However, this challenge should not mitigate our efforts to continue investigation in this area, as there are millions of women, whose numbers continue to rise due to advances in healthcare and disability management, who are entering or will soon enter the menopause transition with little understanding of if and how their experience may be influenced by disability, and vice versa, both positively and negatively. There also may be much that women with a lifelong physical disability can teach their nondisabled peers about thriving in spite of physical and other losses and about the changes in life that can accompany menopause.

\section{ACKNOWLEDGMENTS}

We express our sincere thanks to the participants of this study for their enthusiasm and generosity in sharing their experience. Very special thanks to our tireless research assistant, Martha Ellen, R.N.

\section{REFERENCES}

1. Welner SL. Gynecologic care and sexuality issues for women with disabilities. Sex Disabil 1997;15:33.

2. Welner SL, Simon JA, Welner B. Maximizing health in menopausal women with disabilities. Menopause 2002;9:208.
3. Kuh D, Hardy R, Rodgers B, Wadsworth MEJ. Lifetime risk factors for women's psychological distress in midlife. Soc Sci Med 2002;55:1957.

4. Mishra G, Kuh D. Perceived change in quality of life during the menopause. Soc Sci Med 2006;62:93.

5. Avis NE, Assmann SF, Kravitz HM, Ganz PA, Ory M. Quality of life in diverse groups of midlife women: Assessing the influence of menopause, health status and psychosocial and demographic factors. Qual Life Res 2004;13:933.

6. Greene J. The psychosocial vulnerability model of the menopause. In: Aso T, Yanaihara T, Fujimoto S, eds. The menopause at the millenium: The 9th International Menopause Society World Congress on the Menopause. New York: Parthenon Publishing Group, 1999:216.

7. Bosworth H, Bastian L, Kughbhatla M, et al. Depressive symptoms, menopausal status, and climacteric symptoms in women at midlife. Psychosom Med 2001;63:603.

8. Bosworth HB, Bastian LA, Rimer BK, Siegler IC. Coping styles and personality domains related to menopausal stress. Womens Health Issues 2003;13:32.

9. Greene J. The social and psychological origins of the climacteric syndrome. Brookfield, VT: Gower Publishers, 1984.

10. Greene J, Cooke D. Life stress and symptoms at the climacterium. Br J Psychiatry 1980;136:486.

11. Greene J, Visser A. Longitudinal studies: Comparative conclusions. Maturatis 1992;14:157.

12. Jubelt B, Agre JC. Characteristics and management of postpolio syndrome. IAMA 2000;284:412.

13. Halstead L. New health problems in persons with polio. In: Halstead L, Naierman N, eds. Managing postpolio syndrome: A guide to living well with post-polio syndrome. Washington, DC: NRH Press, 1998.

14. Nosek M, Howland C. Breast and cervical cancer screening among women with physical disabilities. Arch Phys Med Rehabil 1997;78:S39.

15. Nosek MA. Overcoming the odds: The health of women with physical disabilities in the United States. Arch Phys Med Rehabil 2000;81:135.

16. Nosek MA, Howland C, Rintala DH, Young ME, Chanpong GF. National study of women with physical disabilities: Final report. Sex Disabil 2001;19:5.

17. Bruno R, Frick N. Stress and "type $\mathrm{A}^{\text {" behavior as }}$ precipitants of post-polio sequelae: The Felician/Columbia Survey. In: Halstead L, Wiechers D, eds. Research and clincal aspects of the late effects of poliomyelitis. White Plains, NY: March of Dimes Birth Defects Foundation, Original Article Series, 1986;23: 145.

18. Scheer J, Luborsky MR. The cultural context of polio biographies. Orthopedics 1991;14:1173.

19. Silver J. Post-polio syndrome: A guide for polio survivors and their families. New Haven, CT: Yale University Press, 2001.

20. Wennenberg S, Ahlstrom G. Illness narratives of persons with post-polio syndrome. J Adv Nurs 2000;31: 354. 
21. Schanke AK, Lobben B, Oyhaugen S. The Norwegian Polio Study 1994 part II: Early experiences of polio and later psychosocial well-being. Spinal Cord 1999; 37:515.

22. Kemp BJ, Adams BM, Campbell ML. Depression and life satisfaction in aging polio survivors versus agematched controls: Relation to postpolio syndrome, family functioning, and attitude toward disability. Arch Phys Med Rehabil 1997;78:187.

23. Kling C, Persson A, Gardulf A. The health-related quality of life of patients suffering from the late effects of polio (post-polio). J Adv Nurs 2000;32:164.

24. Kemp BJ, Krause JS. Depression and life satisfaction among people ageing with post-polio and spinal cord injury. Disabil Rehabil 1999;21:241.

25. Ahlstrom G, Karlsson U. Disability and quality of life in individuals with postpolio syndrome. Disabil Rehabil 2000;22:416.

26. Bach JR, Campagnolo DI. Psychosocial adjustment of postpoliomyelitis ventilator assisted individuals. Arch Phys Med Rehabil 1992;73:934.

27. Hansson B, Ahlstrom G. Coping with chronic illness: A qualitative study of coping with postpolio syndrome. Int J Nurs Stud 1999;36:255.

28. Lowman CL, Seidenfeld MA. A preliminary report of the psychosocial effects of poliomyelitis. I Consult Psychol 1947;11:30.

29. Schanke HK. Psychological distress, social support and coping behavior among polio survivors: A 5-year perspective on 63 polio patients. Disabil Rehabil 1997;19:108.

30. Diener E, Emmons R, Larsen R, Griffin S. The Satisfaction with Life Scale. J Pers Assess 1985;41:71.

31. Watson D, Clark L, Tellegen A. Development and validation of brief measures of positive and negative affect: The PANAS scales. J Pers Soc Psychol 1988;54:1063.

32. Jette A, Davies A. The Functional Status Questionnaire: Reliability and validity when used in primary care. J Gen Intern Med 1986;1:143.

33. Kalpakjian C, Toussaint L, Klipp D, Forchheimer M. Development and factor analysis of an index of postpolio sequelae. Disabil Rehabil 2005;27:1225.

34. Perz J. Development of the Menopause Symptom List: A factor analytic study of menopause-associated symptoms. Women Health 1997;25:53.

35. Kalpakjian C, Toussaint L, Quint E, Reame N. Use of a standardized menopause symptom rating scale in a sample of women with physical disabilities. Menopause 2005;12:78.

36. Greene J. Constructing a standard climacteric scale. Maturatis 1998;29:25.

37. Freeman EW, Sammel MD, Liu L, Martin P. Psychometric properties of a menopausal symptom list. Menopause 2003;10:258.

38. Kline R. Principles and practice of structural equation modeling. New York: Guilford, 1998.

39. Hu L, Bentler P. Cutoff criteria for fit indexes in covariance structure analysis: Conventional criteria versus new alternatives. Structural Equation Modeling 1999;6:1.
40. Preacher K, Leonardelli G. Calculation for the Sobel test: An interactive calculation tool for mediation tests [computer software]. Available at www.unc.edu/ $\sim$ preacher/sobel/sobel.htm

41. Sprangers MAG, Schwartz CE. Integrating response shift into health-related quality of life research: A theoretical model. Soc Sci Med 1999;48:1507.

42. Myers D, Diener E. The pursuit of happiness. Sci Am 1996;274:70.

43. Heckhausen J, Schulz R. A life-span theory of control. Psychol Rev 1995;102:284.

44. Dijkers M. Correlates of life satisfaction among persons with spinal cord injury. Arch Phys Med Rehabil 1999;80:867.

45. Caltabiano M, Holzheimer M. Dispositional factors, coping and adaptation during menopause. Climacteric 1999;2:21.

46. Lazarus R, Folkman S. Stress, appraisal and coping. New York: Springer Publishing Co., 1984.

47. Ahlstrom G, Wenneberg S. Coping will illness-related problems in persons with progressive muscular diseases: The Swedish version of the Ways of Coping Questionnaire. Scand J Caring Sci 2002;16:368.

48. Kuh DL, Wadsworth M, Hardy R. Women's health in midlife: The influence of the menopause, social factors and health in earlier life. Br J Obstet Gynaecol 1997;104:923.

49. Hardy R, Kuh D. Change in psychological and vasomotor symptom reporting during the menopause. Soc Sci Med 2002;55:1975.

50. Hardy R, Kuh D. Social and environmental conditions across the life course and age at menopause in a British birth cohort study. Br J Obstet Gynaecol 2005; 112:346.

51. Hardy R, Kuh D, Wadsworth M. Smoking, body mass index, socioeconomic status and the menopausal transition in a British national cohort. Int J Epidemiol 2000;29:845.

52. Garber M. Some emotional aspects of poliomyelitis. Public Health Nurs 1952;44:340.

53. Cohen E. A medical-social workers approach to the problem of poliomyelitis. Am J Public Health 1948;38: 1092.

54. Bruno RL, Frick NM. The psychology of polio as prelude to postpolio sequelae-Behavior modification and psychotherapy. Orthopedics 1991;14:1185.

55. Conrady LJ, Wish JR, Agre JC, Rodriquez AA, Sperling KB. Psychologic characteristics of polio survivors-A preliminary report. Arch Phys Med Rehabil 1989;70:458.

56. Hollingsworth L, Didelot M, Levington C. Postpolio syndrome: Psychological adjustment to disability. Issues Ment Health Nurs 2002;23:135.

57. Clark K, Dinsmore S, Grafman J, Dalakas MC. A personality profile of patients diagnosed with postpolio syndrome. Neurology 1994;44:1809.

58. Schanke A, Stangelle J. Fatigue in polio survivors. Spinal Cord 2001;39:243.

59. Tate DG, Forchheimer M, Kirsch N, Maynard F, Roller A. Prevalence and associated features of depression 
and psychological distress in polio survivors. Arch Phys Med Rehabil 1993;74:1056.

60. Thoren-Jonsson AL, Grimby G. Ability and perceived difficulty in daily activities in people with poliomyelitis sequelae. J Rehabil Med 2001;33:4.

61. Tate D, Kirsch N, Maynard F, et al. Coping with the late effects-Differences between depressed and nondepressed polio survivors. Am J Phys Med 1994;73:27.

62. Berlly MH, Strauser WW, Hall KM. Fatigue in postpolio syndrome. Arch Phys Med Rehabil 1991;72:115.

63. Crimmins EM, Kim JK, Hagedorn A. Life with and without disease: Women experience more of both. I Women Aging 2002;14:47.

64. Thoren-Jonsson AL. Coming to terms with the shift in one's capabilities: A study of the adaptive process in persons with poliomyelitis sequelae. Disabil Rehabil 2001;23:341.

65. Cooper AF. Whose illness is it anyway? Why patient perceptions matter. Int J Clin Pract 1998;52:551.

Address reprint requests to: Claire Z. Kalpakjian, Ph.D. Research Investigator

Department of Physical Medicine and Rehabilitation University of Michigan 300 N. Ingalls, NI 2 A09

Ann Arbor, MI 48109

E-mail: clairez@umich.edu 